\title{
PROBLEMATIZAČ̃̃O DA PRÁTICA NA EDUCAÇÃO INFANTIL: RELAÇÕES ENTRE O CURRÍCULO VIVIDO E A EDUCAÇÃO AMBIENTAL
}

\author{
Flavia Grecco Resende ${ }^{1}$ \\ Denise Regina da Costa Aguiar ${ }^{2}$ \\ Leonice Domingos dos Santos Cintra Lima ${ }^{3}$ \\ Cristina Veloso de Castro ${ }^{4}$
}

Resumo: A partir da concepção freireana de educação emancipatória, tendo como questão norteadora a análise da relação entre o currículo prescrito e o vivenciado no cotidiano da Educação Infantil (EI), buscou-se investigar os saberes e práticas em Educação Ambiental (EA) desenvolvidos El com vistas ao desenvolvimento de boas práticas educativas. Como percurso metodológico optou-se pela pesquisa qualitativa de cunho exploratório e documental; em fontes secundárias, realizada em escola pública municipal da cidade de São Paulo. Evidenciou-se possibilidades de formação integral da criança como um sujeito ecológico transformador de sua realidade. Como resultado da discussão, propõe-se a construção do jogo ecológico "Trilha dos Animais Silvestres".

Palavras-chave: Movimento Curricular; Educação Ambiental Crítica; Infância; Jogo Socioeducativo.

Abstract: From the Freirean conception of emancipatory education, having as a guiding question the analysis of the relationship between the prescribed curriculum and that experienced in the daily life of Early Childhood Education (EI), we sought to investigate, the knowledge and practices in Environmental Education (AE) EI developed with a view to developing good educational practices. As a methodological path, qualitative research of exploratory and documentary nature was chosen; in secondary sources, held at a public public school in the city of São Paulo. Possibilities for the integral education of the child as an ecological subject transforming his reality were evidenced. As a result of the discussion, it is proposed to build the ecological game "Wild Animal Trail".

Keywords: Curricular Movement; Critical Environmental Education; Childhood; Socio-educational Game.

\footnotetext{
${ }^{1}$ Universidade Brasil. Email: flavia.resende@ub.edu.br, Link para o lattes: http://lattes.cnpq.br/3896273265457388

2 Universidade Brasil. Email: denise.aguiar@ub.edu.br, Link para o lattes: http://lattes.cnpq.br/3825835597960275

${ }^{3}$ Universidade Brasil. Email: leonice.lima@ub.edu.br, Link para o lattes: http://lattes.cnpq.br/0391005456034509

4 Universidade Brasil. Email: cristina.castro@ub.edu.br, Link para o lattes: http://lattes.cnpq.br/6448783790311393
} 


\section{Introdução}

A educação infantil (EI), ao longo de sua história, sofreu transformações culturais, sociais, pedagógicas e necessita ser organizada como uma etapa primordial para a formação integral e da personalidade das crianças.

O Currículo da Cidade da Educação Infantil do município de São Paulo (CC), implementado a partir de janeiro de 2019, apresentou princípios norteadores da prática pedagógica e para a construção do conhecimento, alicerçado em situações de aprendizagens desafiadoras em que as crianças têm a possibilidade de exercer seu protagonismo, sua criatividade e sua curiosidade e, por meio de situações problemas, criar hipóteses acerca do objeto a ser investigado em busca de respostas.

É que o processo de aprender, em que historicamente descobrimos que era possível ensinar como tarefa não apenas embutida no aprender, mas perfilada em si, com relação a aprender, é um processo que pode deflagrar no aprendiz uma curiosidade crescente, que pode torná-la mais e mais criador. $\mathrm{O}$ que quero dizer é o seguinte: quanto mais criticamente se exerça a capacidade de aprender tanto mais se constrói e desenvolve o que venho chamando "curiosidade epistemológica", sem a qual não alcançamos o conhecimento cabal do objeto (FREIRE, 1996, p.27).

Segundo Freire (1996) romper com a concepção bancária de educação, com o ensino tradicional implica em estimular a curiosidade da criança, permitir que todos os envolvidos no processo de aprendizagem possam construir saberes a partir de situações problemas e de modo crítico.

$\mathrm{Na}$ verdade, a curiosidade ingênua que, "desarmada", está associada ao saber do senso comum, é a mesma curiosidade que, criticizando-se, aproximando-se de forma cada vez mais metodicamente rigorosa do objeto cognoscível, se torna curiosidade epistemológica. Iluda de qualidade, mas não de essência (FREIRE, 1996, p.34).

Os documentos oficiais que normatizam a educação infantil no município de São Paulo, propugnam uma concepção de Educação Ambiental crítica que objetiva a mudança de valores e atitudes na formação de crianças como sujeitos ecológicos, vislumbrando a construção de uma sociedade mais justa, humana e sustentável.

Reigota (2014) afirma que: 
[...] a Educação Ambiental deve procurar favorecer e estimular possibilidades de se estabelecer coletivamente uma "nova aliança" (entre seres humanos e a natureza e entre nós mesmos) que possibilite a todas as espécies biológicas (inclusive a humana) a sua convivência e sobrevivência com dignidade. [...] a EA deve ser entendida como educação política, no sentido que ela reivindica e prepara os cidadãos e cidadãs para exigir e construir uma sociedade com justiça social, cidadanias (nacional e planetária), autogestão e ética nas relações sociais e com a natureza (REIGOTA, 2014, p. 14).

A EA crítica dialoga com o proposto nos dezessete Objetivos de Desenvolvimento Sustentável (ODS), presentes na Agenda 2030 da Organização das Nações Unidas (ONU).

A educação para o desenvolvimento sustentável, trazido pela Agenda 2030/ONU, contempla estes e outros princípios e conceitos, organizados em dezessete Objetivos de Desenvolvimento Sustentáveis (ODS), que se referem às dimensões ambiental, social e econômica. Todos esses princípios, compromissos, conceitos e políticas educacionais unem-se ao compromisso de uma educação que traz a democracia como pressuposto de uma escola pública que se deseja comprometida com a qualidade da formação humana, transformadora e emancipadora (SÃO PAULO, 2019, p. 65).

O documento Currículo da Cidade de São Paulo tem por objetivo favorecer a reflexão crítica e a formação de uma identidade em termos de EA nas ações cotidianas da educação infantil.

Identifica-se que o desafio consiste em estabelecer uma relação entre o currículo prescrito e o currículo vivenciado, portanto destaca-se como problema de pesquisa: a) Os saberes e práticas desenvolvidos na El refletem a concepção crítica do currículo para a EA? b) Como a concepção crítica do currículo permite a formação integral de crianças como sujeitos e transformadoras de sua realidade? c) $O$ jogo possibilita o desenvolvimento de habilidades e a aquisição de conhecimentos para a formação de sujeitos ecológicos?

A presente pesquisa buscou investigar os saberes e práticas, em Educação Ambiental (EA) desenvolvidos na Educação Infantil (EI), em uma escola da Secretaria Municipal da Educação de São Paulo- SME/SP. Para o alicerce deste objetivo foram cumpridas as seguintes etapas de investigação dos saberes e práticas da EA, a análise documental e a proposta de desenvolvimento de um jogo.

Num primeiro momento, investiga-se os saberes e práticas em EA, em uma perspectiva crítica, desenvolvidos na El, numa escola da Secretaria Municipal de Educação de São Paulo (SME-SP).

Revbea, São Paulo, V.16, № 5: 309-327, 2021.

revista brasileira

educação ambiental 
Em seguida, analisa-se os documentos oficiais, documentos da escola, Projeto Político Pedagógico (PPP), os projetos didáticos desenvolvidos ao longo do segundo semestre do ano letivo de 2019 e os registros pedagógicos elaborados pelas professoras nos horários coletivos de formação.

E por último, propõe-se o desenvolvimento de um jogo de tabuleiro, com o intuito de discutir as práticas e ressignificá-las de modo lúdico, tanto para professores como para as crianças da El.

Levanta-se como hipótese que os conteúdos dos documentos oficiais e documentos da escola apresentam saberes e práticas em EA que possibilitam a formação integral da criança como sujeitos ecológicos.

O desenvolvimento dos procedimentos de investigação fundamenta-se em autores que apresentam os subsídios teóricos necessários para a discussão do objeto analisado neste estudo, dentro de uma perspectiva crítica de educação e consequentemente de EA. Baseia-se em referências que dialogam com as análises realizadas ao longo desse estudo.

Para subsidiar a discussão, considerou-se nos registros a observação das professoras, a escuta das crianças, a dialogicidade entre os envolvidos nas situações problematizadoras, o protagonismo infantil e docente, a curiosidade da criança na formulação de hipóteses sobre o meio ambiente e como as professoras desenvolveram metodologias de pesquisa científica para desenvolver os projetos a partir de um tema gerador e do interesse das crianças.

\section{Métodos}

A partir da revisão da literatura selecionada, considerou-se os pressupostos teóricos da temática da EA e da El em uma perspectiva crítica que foram organizados para que as leituras seguissem critérios de acordo com a análise do conteúdo observado nos registros. Para a análise dos conteúdos, utilizou-se os fundamentos propostos por Bardin (2011), o que permitiu a análise dos conteúdos observados na prática pedagógica das professoras da Escola Municipal de Educação Infantil (EMEI).

De acordo com Bardin (2011)

O que é a análise de conteúdo atualmente? Um conjunto de instrumentos metodológicos cada vez mais sutis em constante aperfeiçoamento, que se aplicam a 'discursos' (conteúdos e continentes) extremamente diversificados. $O$ fator comum dessas técnicas múltiplas e multiplicadas - desde o cálculo de frequências que fornece dados cifrados, até a extração de estruturas traduzíveis em modelos - é uma hermenêutica controlada, baseada na dedução: a inferência (BARDIN, 2011, p. 15). 
documental. Já a segunda apresenta as temáticas da discussão do objeto de estudo pesquisado. Entende-se que as tabelas contribuíram como fontes de informações importantes que organizaram a revisão da literatura proposta no estudo.

Tabela 1: Classificação e síntese do material para revisão da literatura e análise documental.

\begin{tabular}{|c|c|c|}
\hline \multicolumn{3}{|c|}{ Caracterização do Material } \\
\hline Classificação & Publicação & Caracterização do Conteúdo \\
\hline $\begin{array}{l}\text { Literatura relativa ao tema } \\
\text { estudado }\end{array}$ & $\begin{array}{l}\text { Dissertações e Teses } \\
\text { Artigo Científico } \\
\text { Capítulos de Livros }\end{array}$ & $\begin{array}{l}\text { Revisão da Literatura } \\
\text { Estado atual da arte }\end{array}$ \\
\hline Documentos Oficiais & $\begin{array}{c}\text { Legislação } \\
\text { Currículo } \\
\text { Instrução Normativa } \\
\text { Projeto Político Pedagógico } \\
\text { Atas } \\
\text { Portfólio }\end{array}$ & $\begin{array}{l}\text { Documento Oficial } \\
\text { Orientação Normativa } \\
\text { Registros do processo } \\
\text { formativos e pedagógico }\end{array}$ \\
\hline
\end{tabular}

Fonte: Autoria própria (2020).

Tabela 2: Temáticas que compreendem o objeto de pesquisa de estudo.

\begin{tabular}{|c|c|c|}
\hline Tema & Autores & Descrição do Material \\
\hline Currículo & $\begin{array}{l}\text { José Gimeno Sacristán } \\
\text { Tomas Tadeu da Silva }\end{array}$ & Concepção Crítica do Currículo \\
\hline $\begin{array}{l}\text { Formação } \\
\text { Docente }\end{array}$ & $\begin{array}{c}\text { Paulo Freire } \\
\text { Maurice Tardif }\end{array}$ & $\begin{array}{c}\text { Reflexão sobre os saberes e práticas } \\
\text { pedagógicas }\end{array}$ \\
\hline$E A$ & $\begin{array}{c}\text { Philippe Pomier Layrargues } \\
\text { Marcos Reigota }\end{array}$ & Dimensões da EA \\
\hline Jogos & Tizuko Morchida Kishimoto & Jogos, brinquedos e brincadeiras \\
\hline
\end{tabular}

Fonte: Autoria própria (2020).

A organização das obras referenciadas e dos documentos para investigação permitiu identificar os autores adequados para a discussão de cada um dos aspectos analisados nessa pesquisa. Num primeiro momento, fundamentou-se as práticas a partir de uma reflexão crítica do currículo, em Sacristán (2008) e Silva (2014). Os estudos desenvolvidos por esses autores, teorizam a prática docente e subsidiam a ideia de um currículo que considere 0 protagonismo infantil e docente refletindo um currículo vivenciado.

Freire (1996) e Tardiff (2014), subsidiam a análise dos registros, resultados das reuniões de formação docente. Buscou-se refletir na teoria se as práticas foram significativas e ultrapassaram os muros da escola, se ampliaram o conhecimento de mundo e compreender se ocorreu o bom uso dos materiais, tempos e espaços, numa perspectiva sustentável.

Para subsidiar a pesquisa sobre a EA o estudo foi embasado em Layrargues (2004) e Reigota (2010). Os pesquisadores trazem contribuições significativas para análise das ações desenvolvidas durante os projetos em uma perspectiva crítica de EA. 
Kishimoto (2010), apresenta-se como um importante referencial na discussão sobre o jogo na El. Sua teoria sobre jogos, brinquedos e brincadeiras ressalta o papel pedagógico do jogo na construção de saberes com a criança respeitando o universo lúdico infantil, evidenciando-se o jogo como um instrumento indispensável da prática pedagógica.

\section{Resultados e Discussão}

Observa-se que o currículo da El apresenta conteúdos significativos de $E A$ e, quando as crianças colocam em jogo tudo o que sabem e pensam sobre o conteúdo a ser estudado, desenvolvem o senso crítico e constroem saberes de modo significativo e de uso social, tornando-se protagonistas e agentes de transformação social.

A potência criativa e o protagonismo são possíveis quando transformamos nossas crenças, quando damos vez e escutamos a voz das crianças nos territórios, acreditando que novas culturas infantis produzirão novas culturas adultas culturas essas mais justas e humanas para uma sociedade que ainda não existe (SÃO PAULO, 2019, p. 54).

Nesse sentido, observa-se, por meio dos registros, se houve a ressignificação de saberes e práticas desenvolvidos na El, sob uma perspectiva crítica de EA. Ao debruçar-se sobre os relatos produzidos na Jornada Integral de Formação - JEIF ${ }^{5}$, percebe-se que a possibilidade de situações de aprendizagem intelectualmente estimulantes e de relevância social se tornam indispensáveis na construção do conhecimento na El.

É preciso que, pelo contrário, desde os começos do processo, vá ficando cada vez mais claro que, embora diferentes entre si, quem forma se forma e re-forma ao formar e quem é formado forma-se e forma o ser formado. É nesse sentido que ensinar não é transferir conhecimentos, conteúdos nem formar é ação pela qual um sujeito criador dá forma, estilo ou alma a um corpo indeciso e acomodado. Não há docência sem discência, as duas se explicam e seus sujeitos, apesar das diferenças que os conotam, não se reduzem à condição de objeto, um do outro. Quem ensina, ensina alguma coisa a alguém (FREIRE, 1996, p. 25).

5 A Jornada Especial Integral de Formação (JEIF) é umas das opções de jornada de trabalho para os docentes da Rede Municipal de Educação de São Paulo. A jornada de trabalho 25 (vinte e cinco) horas aula e 15 (quinze) horas adicionais para formação, correspondendo a 240 (duzentas e quarenta) horas aula mensais. 
Identifica-se nos registros das reuniões de formação que, o estudo do CC, promoveu a reflexão sobre a prática pedagógica e o desenvolvimento de boas situações de aprendizagem.

Pode-se observar, também, que a investigação em torno de situações problemas que foram propostas e desenvolvidas pelas professoras em sua prática, dialogando diretamente com a concepção de EA crítica.

O professor é que precisa compreender o caminho de aprendizagem que o aluno está percorrendo naquele momento e, em função disso, identificar as informações e as atividades que permitam a ele avançar do patamar de conhecimento que já conquistou para outro mais evoluído. Ou seja, não é o processo de aprendizagem que deve se adaptar ao de ensino, mas o processo de ensino é que tem de se adaptar ao de aprendizagem, Ou melhor: o processo de ensino deve dialogar com o de aprendizagem (WEISZ, 2009, p. 65).

Por meio dos relatos, percebe-se que, para a mudança de atitude das professoras em ressignificar a prática pedagógica na $\mathrm{El}$, foi preciso intensificar $\mathrm{O}$ exercício da escuta e a interação com as crianças. A intencionalidade em dar vez e voz às falas infantis foram fundamentais para que os projetos fossem, de fato, protagonizados pelos educandos. Observa-se, também, que esse exercício só foi possível a partir do estudo do CC e de toda a documentação pedagógica. Ressalta-se, ainda, que o referencial teórico dos documentos apresenta a concepção freireana de educação.

Por meio dos registros, identifica-se que, durante o processo formativo e construção de novas práticas, houve todo um movimento de reorganização de tempos e espaços na EMEI. Essa reorganização possibilitou uma boa circulação de informações e discussões no que tange a consolidação da escuta, protagonismo e autoria infantil.

A narrativa inventa outra lógica de formação. Quando narramos sobre nossas experiências, nos transformamos. Ao narrarmos uma história, acabamos por fazer a escuta da nossa própria experiência. Do mesmo modo, quando escutamos a narrativa do outro, somos tocados por ela, podemos dialogar e refletir, incorporando-a ou não em nossa experiência. Neste documento de orientação curricular, é preciso pensar as cenas como "narrativas-mestres", porque são promotoras de significados que abrem para a criação de outras narrativas. (SÃO PAULO, 2019, p.16)

Nesse sentido, pode-se identificar que as práticas educativas passaram a refletir a proposta do $\mathrm{CC}$. Por meio da leitura do relato de outros profissionais da rede municipal de ensino, identificou-se que as professoras puderam ressignificar sua própria prática. Nota-se que o $\mathrm{CC}$, não só possibilitou 0 
compartilhamento de boas práticas da rede municipal, como também sistematizou e socializou estratégias bem sucedidas.

\section{Currículo da Cidade da Educação Infantil}

A partir da análise do CC, entende-se que a SME-SP, assume o compromisso com a Organização das Nações Unidas para Educação, Ciência e Cultura (UNESCO) em desenvolver práticas para uma vida sustentável, pacífica, próspera e equitativa na Terra, para todos, agora e no futuro. A matriz dos saberes estabelecidos no CC fundamenta-se em marcos legais e documentos oficiais socialmente relevantes, os quais indicam elementos imprescindíveis de serem inseridos em propostas curriculares alinhadas com conquistas relacionadas aos direitos humanos, em geral, e ao direito à educação em específico (SÃO PAULO, 2019).

Sacristán (2000), observa que a teorização sobre o currículo deve ocupar-se necessariamente das condições de realização do mesmo, da reflexão sobre a ação educativa nas instituições escolares, em função da complexidade que se deriva do desenvolvimento e realização do mesmo.

O currículo, como projeto baseado num plano construído e ordenado, relaciona a conexão entre determinados princípios e realização dos mesmos, algo que se há de comprovar e que nessa expressão prática concretiza seu valor. É uma prática na qual se estabelece um diálogo, por assim dizer, entre agente sociais, elementos técnicos, alunos que reagem frente a ele, professores que o modelam e etc. Desenvolver esta acepção do currículo como âmbito prático tem o atrativo de poder ordenar em torno desse discurso as funções que cumpre o modo como as realiza, estudando-o processualmente: se expressa numa prática e ganha significado dentro de uma prática de algum modo prévio e que não é apenas função do currículo, mas de outros determinantes. É o contexto da prática, ao mesmo tempo que é contextualizado por ela (SACRISTÁN, 2000, p.16).

Nesse sentido, espera-se que o documento seja vivenciado no cotidiano da escola, e que o currículo revele de fato características de toda a comunidade educativa.

O currículo é uma opção historicamente configurada, que se sedimentou dentro de uma determinada trama cultural, política, social e escolar; está carregado, portanto de valores e pressupostos que é preciso decifrar (SACRISTÁN, 2000, p.17).

Entende-se que a matriz de saberes tem como propósito formar cidadãos éticos, responsáveis e solidários que fortaleçam uma sociedade mais inclusiva, democrática, próspera e sustentável, e indica o que bebês, crianças, 
adolescentes, jovens e adultos devem aprender e desenvolver ao longo do seu processo de escolarização (SÃO PAULO, 2019). Destaca-se como relevante para esta discussão que, os princípios da matriz de saberes, conservam as três dimensões presentes na $E A$ : conhecimentos, valores e participação. Percebe-se, igualmente, que as dimensões articuladas entre si potencializam o desenvolvimento de boas práticas e corroboram para a construção de sujeitos ecológicos.

Entende-se que o conceito para a sustentabilidade apresentado no CC, subsidiado teoricamente na Agenda 2030, não está restrito somente à discussão da dimensão de EA. Os dezessete ODS remetem, também, às dimensões social e econômica, ou seja, identificam-se as três dimensões do desenvolvimento sustentável.

Os ODS abrangem ações voltadas a cinco grandes áreas: Pessoas, Planeta, Paz, Prosperidade e Parcerias. Essa abrangência reflete uma visão holística do ser humano e dos desafios globais visando assegurar a sustentabilidade das diversas formas de vida no planeta. Cada um dos 17 ODS é detalhado em metas e ações específicas que tratam de aspirações globais acordadas, a serem alcançadas até 2030. Foram estabelecidas 169 metas a serem incorporadas nos processos, políticas e estratégias de planejamento em diferentes níveis (internacional, nacional e local) de maneira coerente entre si. Esta Agenda compõe assim uma declaração do reconhecimento da urgência em se tomar medidas transformadoras na direção do desenvolvimento sustentável, compreendendo o contexto atual de interdependência global das ações (SÃO PAULO, 2019, p.58).

\section{Documentação Pedagógica da Educação Infantil}

A Instrução Normativa SME-SP no 2, publicada em fevereiro de 2019, orienta os registros relacionados ao desenvolvimento das crianças na El para o ano letivo de 2019. A partir da publicação do CC, as orientações em relação aos registros na El, passaram a adotar alguns critérios quanto a sua elaboração para que revelassem de fato toda a riqueza das situações de aprendizagens propostas no cotidiano da educação infantil.

A partir da multiplicidade de instrumentos de registros utilizados pelas Unidades Educacionais (UE) da Rede Municipal de Ensino (RME) - planejamento, carta de intenção, semanário, diário de bordo, caderno de observação, caderno de passagem, portfólio, mural, painel, agenda, redes sociais, relatório individual do bebê e da criança, registros de reuniões e horários formativos, projeto político-pedagógico, entre outros - e os diferentes usos destes instrumentos no cotidiano dos Centros de Educação Infantil (CEI) diretos e parceiros (indiretos e particulares), dos Centros 
Municipais de Educação Infantil (CEMEI), dos Centros de Educação Infantil Indígena (CEII), das Escolas Municipais de Educação Infantil (EMEI) e das Escolas Municipais de Educação Bilíngue para Surdos (EMEBS) fez-se necessário a elaboração de uma Orientação Normativa que trata de registros na Educação Infantil (SÃO PAULO, 2019, p.2).

De acordo com a Instrução Normativa № 2 de fevereiro de 2019, diariamente são desenvolvidas atividades na educação infantil, portanto os registros do desenvolvimento das aprendizagens das crianças devem romper com a ideia burocrática e avançar no sentido de potencializar as ações formativas.

Por isso, os registros devem ser considerados como instrumentos reveladores das práticas cotidianas e como recursos pedagógicos para a ressignificação dessas práticas. Os registros do cotidiano da UE são elaborados pela(o) professora(or) a partir da observação e da escuta de bebês e crianças, bem como da sua prática pedagógica, sendo também subsidiado pelas informações obtidas nas reuniões e nos encontros formativos, coordenados pela equipe gestora. Pertinente também observar a possibilidade de utilizar o diálogo com as famílias/responsáveis por meio de agenda, das redes sociais e/ou da documentação pedagógica. Além do registro $\mathrm{da}(0)$ professora(or), os bebês, as crianças $\mathrm{e}$ as famílias/responsáveis podem ser incentivados a produzir registros (SÃO PAULO, 2019, p.2.).

O principal objetivo deste documento é o de subsidiar as equipes gestoras e docentes na elaboração dos diversos instrumentos de registros das Unidades Educacionais e promover o estudo e a reflexão para que esses instrumentos de registros possam tornar-se documentação pedagógica.

Pode-se constatar que, a partir da observação dos documentos, houve uma significativa evolução dos registros no acompanhamento das aprendizagens das crianças, aprimorando a prática dos professores na El. Compreende-se que, atualmente, o eixo central no processo de construção das aprendizagens é o protagonismo infantil, o trabalho com as múltiplas linguagens, a importância do brincar no cotidiano da El e, portanto, precisam ser explícitos nos registros.

A avaliação na El parte da observação materializada nos registros das experiências vivenciadas pelas crianças em seu processo de construção do conhecimento. As descobertas, inquietações, hipóteses acerca do ambiente são parte integrante do currículo. Nota-se que, nessa relação, é muito importante a atenção dos professores em relação à escuta, o protagonismo e a autoria infantil. Observa-se nos registros as vivências infantis a partir da atenção e escuta da criança pelas professoras, podendo dialogar e refletir sobre o desenvolvimento das aprendizagens.

Revbea, São Paulo, V.16, № 5: 309-327, 2021. 
Os registros mostravam as experiências vividas pelas crianças com relação ao processo de conhecimento e suas descobertas. Para então servir como meio de comunicação entre as instituições de ensino que recebiam as crianças e entre suas(seus) professoras(es), como também evidenciava a família como interlocutor da avaliação (SÃO PAULO, 2019, p 4.).

A partir da análise dos registros na EMEI, pode-se identificar a importância da documentação pedagógica para conhecer as preferências das crianças, seus interesses e a partir dos mesmos estabelecer temas geradores para o desenvolvimento dos projetos pedagógicos.

Em verdade, o conceito "tema gerador" não é uma criação arbitrária, ou uma hipótese de trabalho que deva ser comprovada. "Se o tema gerador" fosse uma hipótese que devesse ser comprovada, a investigação, primeiramente, não seria em torno dele, mas de sua existência ou não (FREIRE, 1983, p. 103).

Pode-se identificar que, os projetos didáticos desenvolvidos na EMEI, fundamentam-se na concepção de educação freireana, tendo o tema gerador como subsídio para a construção de conhecimentos, habilidades e valores. Segundo Freire (1983), embora o tema gerador seja um universo mínimo temático, é de suma importância, pois considera o interesse dos educandos

A normativa corrobora para uma prática pedagógica integradora que tenha como princípio a escuta, a observação e o diálogo e, nesse sentido, nos referenciamos novamente na concepção educacional freireana pois, para o autor, educar é um ato de conhecimento da realidade concreta, das situações vividas, um processo de aproximação crítica da própria realidade: compreender, refletir, criticar e agir são as ações pedagógicas pretendidas (TOZONI-REIS, 2006, p.93).

Paulo Freire, ao tratar do conceito de formação permanente, chama atenção para esse processo formativo e reflexivo, para a conscientização e a práxis, que devem levar ao desenvolvimento profissional dos sujeitos e a melhoria de seus trabalhos e seus contextos: na formação permanente dos professores, o momento fundamental é o da reflexão crítica sobre a prática. É pensando criticamente a prática de hoje ou de ontem que se pode melhorar a próxima prática. O próprio discurso teórico, necessário à reflexão crítica, tem de ser de tal modo concreto que quase se confunda com a prática (SÃO PAULO, 2019 apud FREIRE, 1997, p.39).

Observa-se que a normativa propõe aos docentes o desenvolvimento de registros analíticos, que compreendam as vivências infantis no cotidiano da 
EMEI, para isso, as professoras (es) têm a postura de quem observa, escuta, registra e interpreta o cotidiano de sua turma.

Ao escrever e refletir sobre o escrito que, por sua vez, reflete a prática, o professor pode fazer teoria, tecer pensamento-vida. Escreve o que faz. Pensa o que faz. Compreende o que faz. Repensa o que faz. Redefine o que faz. Reafirma o que faz. Percebe limites e possibilidades de sua prática. Procura alternativas. O registro diário é, pois, um instrumento que articula a ligação entre teoria e prática, entre as aprendizagens já realizadas e os novos conhecimentos (SÃO PAULO, 2019, apud OSTETTO, 2008, p.21).

A Instrução Normativa propõe a adoção de diferentes instrumentos de registro e análise da prática pedagógica, tendo como princípio as vozes infantis e os olhares infantis, nesse sentido, as rodas de conversa destacam-se como prática recorrentes na EMEI.

Segundo o documento, por meio das rodas de conversa, as crianças participam da elaboração dos registros, comunicam e compartilham o que consideram importante nas experiências educativas, tendo sua voz, seu olhar e seus saberes valorizados, podem construir uma memória repleta de significados.

O documento apresenta quatro categorias de registros: para o planejamento do trabalho pedagógico, para a comunicação do trabalho pedagógico; para avaliação das aprendizagens, para a formação permanente; conforme apresenta-se na Tabela 3 , onde os registros foram organizados, a partir da Instrução Normativa nº 02 de fev/2019 SME-SP, 2020.

Tabela 3: Categoria de registros. Categoria de Registros

\begin{tabular}{|c|c|}
\hline $\begin{array}{l}\text { PLANEJAMENTO DO } \\
\text { TRABALHO PEDAGÓGICO }\end{array}$ & $\begin{array}{l}\text { Carta de Intenções } \\
\text { Planejamento Contínuo do trabalho docente } \\
\text { Semanário } \\
\text { Diário de Bordo }\end{array}$ \\
\hline $\begin{array}{l}\text { COMUNICAÇÃO DO } \\
\text { TRABALHO PEDAGÓGICO }\end{array}$ & $\begin{array}{l}\text { Murais, painéis, paredes e muros } \\
\text { Imagens, fotos, vídeos e produções infantis } \\
\text { Redes Sociais Institucionais, } \\
\text { Agenda } \\
\text { Caderno de Passagem } \\
\text { Caderno de observação e registro do bebê e da criança }\end{array}$ \\
\hline $\begin{array}{l}\text { AVALIAÇÃO DAS } \\
\text { APRENDIZAGENS }\end{array}$ & $\begin{array}{l}\text { Relatório do Acompanhamento da Aprendizagem } \\
\text { Portfólio }\end{array}$ \\
\hline FORMAÇÃO & $\begin{array}{l}\text { Registros de reuniões formativas; } \\
\text { Reuniões pedagógicas } \\
\text { Formação permanente/ em serviço para os docentes } \\
\text { Cartas Pedagógicas }\end{array}$ \\
\hline
\end{tabular}


Pode-se observar na documentação pedagógica das professoras/professores da EMEI e identificar os olhares das crianças presentes nos registros, pois ao longo das situações didáticas e projetos analisados constatou-se materiais como filmagens e fotografias produzidas pelas crianças a partir de câmeras digitais (celular).

Com mais frequência verificou-se nos portfólios das professoras, registros por desenhos, colagens, gravuras com materiais não estruturados revelando no registro a visão das crianças em relação à proposta desenvolvida. Nesta perspectiva, considerar o ponto de vista das crianças nos registros supõe uma ruptura de paradigmas adultocentrados, implicando em mudanças nas práticas pedagógicas avaliativas e nos registros das professoras (SÃO PAULO, 2019).

\section{Projeto Político Pedagógico}

Por meio da análise do Projeto Político Pedagógico (PPP) pode-se constatar que toda a documentação pedagógica é o resultado e /ou parte de um processo reflexivo da práxis pedagógica e que é passível de transformações e qualificações a partir das contribuições vindas da prática refletidas na teoria.

Entende-se que o PPP da EMEI reflete a realidade da comunidade escolar, sendo revelador da dinâmica escolar.

Adotar uma ideologia educacional democrática, como pretendemos na gramática pedagógica do currículo progressista e construtiva, como postulada nas pedagogias reformadoras do final do século XIX e do século XX, de Fredrich Froebel, John Dewey, Célestin Freinet, Maria Montessori e Loris Malaguzzi; na psicologia construtivista de Jean Piaget, que remete à compreensão do potencial intelectual do ser humano; e na psicologia socioconstrutivista, de Lev S. Vygotsky e Jerome Bruner, sobre a construção sociocultural do conhecimento. Podem auxiliar nessa caminhada o diálogo com os diferentes modelos curriculares (High Scope; Movimento da Escola Moderna - MEM; Reggio Emilia; Trabalho de Projetos; Associação Criança, Pen Green Centre, entre outros) (SÃO PAULO, 2019, p. 178).Rede Municipal de Ensino de São Paulo, implica compormos uma

Observa-se que o PPP da EMEI reflete a concepção crítica de educação, pois o documento apresenta-se dinâmico e reflete o cotidiano escolar. De acordo com a análise do PPP da EMEI, o documento foi construído no coletivo, ouvindo a comunidade, estudantes e funcionários. Nota-se que a construção do documento foi subsidiada pelo CC e refletida de acordo com a realidade da EMEI, considerando o território ao qual está inserido, respeitando os tempos e espaços da El, e a concepção da Unidade Educativa. 


\section{Projetos Pedagógicos}

Nota-se nos registros analisados que os projetos pedagógicos partiram do interesse das crianças. De acordo com o CC, norteador da práxis pedagógica na El, a escuta atenta das vozes infantis, bem como as elaborações de hipóteses das crianças são reveladoras da concepção de educação que valoriza a construção de conhecimento. Quando as professoras dão atenção aos questionamentos, comentários e sugestões das crianças tornam o processo de aprendizagem significativo.

Para que a organização curricular seja significativa para as crianças, é preciso que ela também seja desafiadora para as(os) professoras(es) e encantadora para as famílias. A ênfase no protagonismo infantil transforma a(o) professora(or) em articuladora(or) do currículo vivido na escola. Cabe a ela(e) colocar em interligação os quatro elementos que compõem a relação pedagógica: as crianças, as(os) educadoras(es), os contextos e a cultura (saberes, linguagens e conhecimentos) (SÃO PAULO, 2019, p. 126).

Percebe-se, também, que os registros dos projetos analisados revelam alguns dos dezessete ODS, bem como as metas estabelecidas para construir um futuro mais sustentável. Identifica-se na análise dos registros que as práticas das professoras envolvidas nos projetos corroboram com os princípios da Agenda de 2030 no que tange aos direitos humanos e do meio ambiente.

Os projetos analisados na EMEI foram desenvolvidos ao longo do ano letivo de 2019. Observa-se pelos registros que o lúdico é elemento central no desenvolvimento dos projetos. Por meio dos projetos analisados, pode-se evidenciar protagonismos infantil e docente no desenvolvimento das temáticas escolhidas a partir do interesse dos envolvidos no estudo.

O projeto pedagógico Parque das Abelhas desenvolveu-se a partir da descoberta de colmeias de abelhas Jataí nas áreas externas da EMEI. Por meio da exploração dos espaços, prática cotidiana na $\mathrm{EI}$, desenvolveu-se alguns passos de uma pesquisa científica com as crianças, considerando o processo de polinização, produção de mel e a estrutura social das colmeias. A partir do tema gerador, levantaram-se as informações e hipóteses das crianças sobre o tema. A partir das hipóteses, iniciou-se o processo de investigação seguindo os passos da pesquisa científica. Apresentou-se diversos materiais de consulta, tais como livros, revistas e internet para pesquisa coletiva e mediada pela professora

A avaliação estabeleceu-se a partir da produção de um diário de bordo com as etapas e os saberes construídos ao longo do projeto sobre o ciclo da polinização e comparação com as hipóteses iniciais apontadas pelas crianças sobre o assunto no início das investigações, apresentado na Tabela 4 a partir de dados coletados no livro de reunião de formação das professoras, 2019. 
Tabela 4: Projeto pedagógico Parque das Abelhas.

\section{PROJETO: Parque das Abelhas}

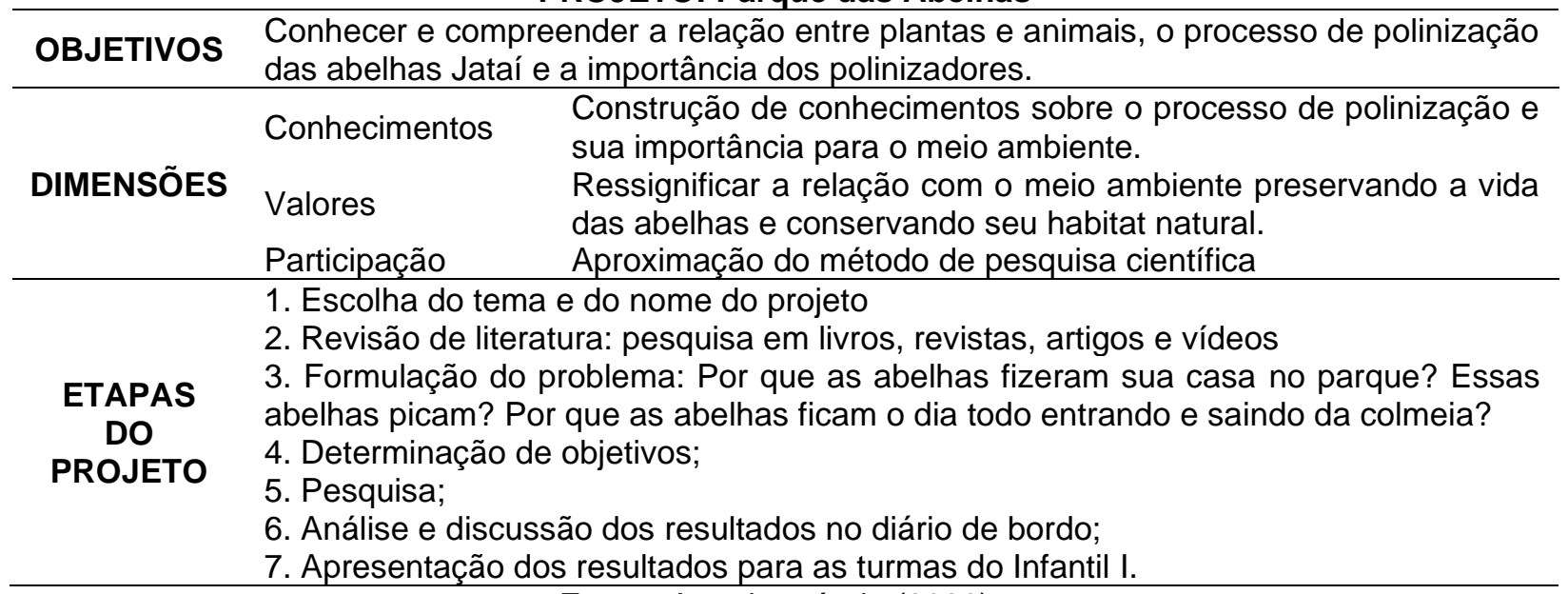

Fonte: Autoria própria (2020).

O projeto pedagógico Reaproveitar e Aproveitar, surgiu da observação e escuta dos hábitos alimentares das crianças e da quantidade de alimentos rejeitados no horário do almoço. Percebe-se nos registros a reflexão coletiva sobre o desperdício de alimentos e o volume de resíduos alimentares no lixo. Partiu-se, portanto dessa reflexão, para ressignificar a relação das crianças com os alimentos, apresentando os grupos alimentares e a importância do reaproveitamento de alimentos.

A avaliação do projeto pautou-se na identificação, ao longo do projeto, na mudança dos hábitos alimentares e na redução no desperdício de alimentos nos momentos de lanche e almoço, apresentados na tabela 5, com dados do livro de reunião de formação das professoras/2019.

Tabela 5: Projeto Pedagógico: Reaproveitar e Aproveitar.

\section{PROJETO: Reaproveitar e Aproveitar}

1. Identificar o desperdício de alimentos no lanche e almoço.

2. Ressignificar a relação das crianças com a comida, construindo saberes

OBJETIVOS sobre os alimentos.

3. Desenvolver oficinas de culinária a partir do reaproveitamento de alimentos.

4. Conscientizar as crianças sobre o desperdício de alimentos.

Conhecimentos Classificação dos alimentos

Valores Consumo sustentável

Participação Elaboração de receitas reaproveitando os alimentos

1. Roda de conversa sobre as preferências alimentares.

2. Classificação dos alimentos e conversa com a nutricionista da EMEI.

3. Pirâmide Alimentar.

ETAPAS 4. Seleção dos alimentos a serem estudados: Carboidratos, Verduras e DO Legumes, Frutas, Leite e derivados, Carnes e Ovos, Leguminosas e

PROJETO oleaginosas, Óleos e Gorduras, Açúcares e Doces.

5. Pesquisa: Receitas.

6. Seleção das receitas.

7. Estudo do Meio: Feira Livre.

8. Oficina culinária: Mini Pizza de Berinjela

Fonte: Autoria própria (2020). 
Nota-se que o Projeto Pedagógico Animais Silvestres partiu da observação da professora pelas preferências das crianças pelos mesmos animais da caixa de brinquedos. A disputa pelos mesmos brinquedos, gerava conflitos que constantemente precisavam ser mediados pela professora. O projeto "Animais Silvestres", apresentado na tabela 6 , teve como objetivo ampliar os saberes das crianças sobre os animais por meio de atividades de pesquisa para ampliar o repertório sobre as espécies silvestres e conhecer as características dos animais por meio de diferentes classificações, tais como espécie, hábitos alimentares e habitat. A tabela (6) foi organizada conforme os dados do livro de reunião de formação das professoras/2019.

Tabela 6: Projeto Pedagógico Animais Silvestres

\begin{tabular}{|c|c|c|}
\hline \multicolumn{3}{|c|}{ PROJETO: Animais Silvestres } \\
\hline OBJETIVOS & Estudo do meio: & Animais do Zoológico \\
\hline \multirow{3}{*}{ Dimensões } & Conhecimentos & Classificação dos Animais Silvestres \\
\hline & Valores & Preservação da fauna \\
\hline & Participação & Estudo do meio \\
\hline $\begin{array}{c}\text { ETAPAS } \\
\text { DO } \\
\text { PROJETO }\end{array}$ & \multicolumn{2}{|c|}{$\begin{array}{l}\text { 1. Roda de conversa sobre os animais. } \\
\text { 2. Classificação dos animais. } \\
\text { 3. Seleção dos animais a serem estudados. } \\
\text { (leão, girafa, onça pintada, jacaré, elefante, hipopótamo). } \\
\text { 4. Pesquisa: fichas técnicas. } \\
\text { 5. Estudo do roteiro do zoológico (mapa/ percurso). } \\
\text { 6. Estudo do Meio: Zoológico- apreciação dos animais selecionados no projeto. }\end{array}$} \\
\hline
\end{tabular}

Fonte: Autoria própria (2020).

\section{Resultado da Pesquisa}

\section{Proposta: Jogo Trilha dos Animais Silvestres}

A partir da observação do projeto Pedagógico Animais Silvestres, pensouse como proposta a produção do material pedagógico Trilha dos Animais Silvestres. A proposta é um jogo de tabuleiro pedagógico para compor o currículo. Pensa-se na proposta de construção do jogo "A Trilha dos Animais Silvestres" a partir do percurso científico trilhado pelas crianças. Observa-se, a partir do portfólio, que as crianças se interessam muito pela temática e, portanto, espera-se que o jogo possa contribuir para a sistematização dos conhecimentos sobre a fauna silvestre.

O mundo social surge quando a criança interage com outras pessoas para aprender e expressar suas brincadeiras. Pular amarelinha, rodar um pião, jogar peteca: primeiro se aprende e depois se brinca. Jogos de tabuleiro e suas regras são criações da sociedade e trazem os valores do ganhar ou perder, comprar e vender. $\mathrm{Na}$ brincadeira do faz de conta, o mundo social aparece na sua temática: ser médico, professora, motorista (KISHIMOTO, 2010, p.12). 
Espera-se com a proposta de criação do jogo de tabuleiro, que o material didático possa validar conhecimentos e informações importantes sobre os animais silvestres, conhecimentos tais como nome popular e científico, habitat natural, hábitos alimentares, período de vida e reprodução.

Pretende-se produzir o jogo "Trilha dos Animais Silvestres", de modo que em cada rodada 4 participantes pudessem jogar. Os materiais necessários para o jogo serão: 1 tabuleiro, 4 peões com miniatura de animais, cartas de perguntas e respostas, 1 dado. A Figura 1 é uma representação do tabuleiro proposto a partir da análise dos registros do Projeto Animais Silvestres. Pretende-se materializar a proposta

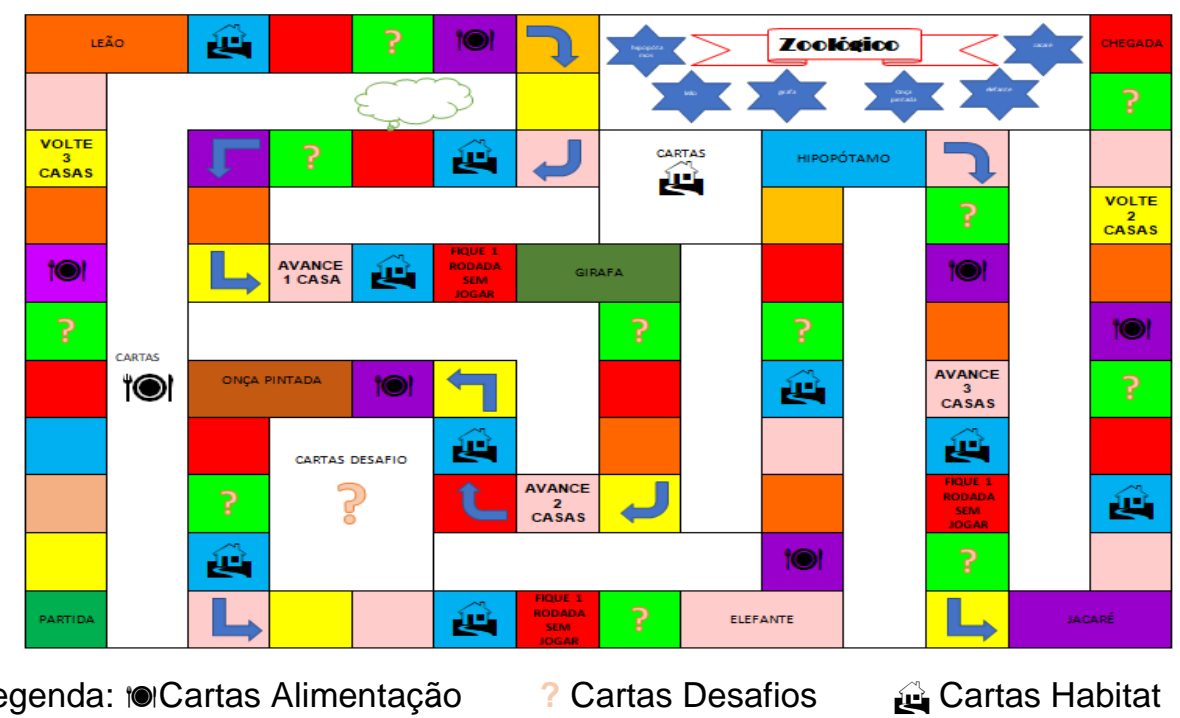

Figura 1: Proposta de tabuleiro para o jogo "Trilha dos Animais"

Fonte: Autoria própria (2020).

Sobre as regras, sabendo a ordem de cada jogador, determinada anteriormente pelo dado (quem tirou o número maior inicia a rodada), o primeiro jogador lança o dado. De acordo com a quantidade tirada no lançamento do dado, percorre pelas casas. Se cair na casa que tem uma miniatura, deve retirar a carta com a questão sobre o animal e responder o que lhe pede. $O$ tabuleiro apresenta algumas regras explícitas, tais como: a) volte as casas; b) avance as casas e c) fique uma rodada sem jogar. Vence o jogo quem chegar à saída primeiro.

\section{Conclusões}

O movimento metodológico desenvolvido ao longo do projeto considerou a concepção de infância presente no currículo da educação infantil, bem como os princípios da E.A crítica. Pode-se observar que o projeto atendeu às ODS presentes na Agenda 2030. Por meio da análise dos registros pode-se constatar que o projeto possibilitou a construção de saberes pedagógicos, tais como, a representação e tabelas e gráficos, noções numéricas, medidas de tempo, 
formas e sólidos geométricas além de possibilitar aprendizagens significativas por meio da resolução de situações problemas, confirmando a hipótese inicial.

Dentre as dimensões analisadas, o conhecimento foi adquirido por meio do percurso que possibilitou a observação, a análise dos dados, a pesquisa do objeto de estudo, o registro e a absorção de conceitos.

Na dimensão de valores, as crianças participaram de um projeto que gerou poucos resíduos sólidos para não impactar o meio ambiente, além de ressignificarem seus saberes em relação à vida silvestre, entendendo a importância da preservação ambiental e a conservação dos biomas para que esses animais possam viver em liberdade em seu habitat natural. Também se aproximaram das discussões referentes ao tráfico de animais silvestres ações mitigadoras para a redução desse tipo de crime ambiental.

Sobre a dimensão da participação, todo o processo compreendeu a escuta, o protagonismo e a autoria infantil. Protagonismo infantil e docente ocorrem de forma simultaneamente, baseada numa relação sociointeracionista, interdependente e colaborativa. Pode-se identificar que durante todo o processo a professora teve uma escuta atenta das necessidades de aprendizagem das crianças, esteve atenta às manifestações, interesses e desafios.

\section{Referências}

BARDIN, L. Análise de Conteúdo. São Paulo: 2011.

FREIRE, P. Pedagogia do Oprimido. Rio de Janeiro: Paz e Terra, 1983.

FREIRE, P. Pedagogia da Autonomia: saberes necessários a prática educativa. Rio de Janeiro: Paz e Terra, 1996.

KISHIMOTO. T. M. (org). Jogo, brinquedo, brincadeira e a educação. São Paulo: Cortez, 2010.

LAYRARGUES, P.P. Identidades da Educação Ambiental brasileira. Brasília: Ministério do Meio Ambiente, 2004.

REIGOTA, M. O que é Educação Ambiental. São Paulo: Brasiliense, 2006.

REIGOTA, M. A Educação Ambiental para além dela mesma. 13 de março de 2008. Disponível em < file:///C:/Users/Notebook/Downloads/972-2045-1-PB.pdf> Acesso em 18 de mai. de 2020.

REIGOTA, M. A Educação Ambiental frente aos desafios apresentados pelos discursos contemporâneos sobre a natureza. Educação e Pesquisa, São Paulo, v.36, n.2, p. 539-553, maio/ago. 2010.

SACRISTÁN, J. G. O Currículo: uma Reflexão sobre a Prática. Porto Alegre: Artmed, 2000. 
SÃO PAULO (Município). Secretaria Municipal de Educação. Instrução Normativa no 02/2019: Dispõe sobre os registros na Educação Infantil. São Paulo: SME/DOT, 2019.

SÃO PAULO (SP). Secretaria Municipal de Educação. Coordenadoria Pedagógica. Currículo da cidade: Educação Infantil. - São Paulo: SME/COPED, 2019.

SILVA, T.T. da. Documentos e identidade: uma introdução às teorias do currículo. 3. ed. - Belo Horizonte: Autêntica Editora, 2014.

TARDIF, M. Saberes docentes e formação profissional. Petrópolis, RJ: Vozes, 2014.

TOZONI-REIS, M. F. de C. Temas ambientais como "temas geradores": contribuições para uma metodologia educativa ambiental crítica, transformadora e emancipatória. Educ. rev., Curitiba, n. 27, p. 93-110, Junho 2006.

WEISZ. T. O diálogo entre o ensino e a aprendizagem. São Paulo: Ática, 2009. 